\title{
Transformer less Bidirectional Grid-Connected Single Power Conversion Converter
}

\author{
Saima $S$ \\ PG Scholar, Dept. of EEE, \\ Govt. Engineering College, \\ Bartonhill, Thiruvananthapuram, \\ India,
}

\author{
Prof. Simi Raj \\ Assistant Professor, Dept. of EEE, \\ Govt. Engineering College, \\ Bartonhill, Thiruvananthapuram, \\ India,
}

\begin{abstract}
A transformer less bidirectional grid connected converter is introduced. This bidirectional converter has a bidirectional dc-dc converter and an unfolding bridge, with a single stage power conversion. Advantages of this converter include single stage power conversion and usage of low battery voltage. Bidirectional power conversion is done by the bidirectional dc-dc converter due to its adaptive controlling functions. The grid voltage is obtained from the unfolding bridge as it converts the rectified sine wave into the grid voltage. The grid current is controlled with a feed forward nominal voltage compensator. Therefore the power conversion efficiency increases. By using this non-isolated topology the voltage gain in buck and boost mode can be increased.
\end{abstract}

\section{Keywords:- Energy storage system (ESS), Non-isolated topology, high efficiency}

\section{INTRODUCTION}

Bidirectional dc-dc converters are important now a days due to the increasing need of bidirectional energy transfer. Apart from the traditional applications the new applications of bidirectional converter include energy storage in interruptible power supplies and renewable energy system. The renewable energy sources like wind, photo-voltaic etc are fluctuating type hence it cannot be use as a single source of power. Energy storage device are commonly used to avoid these fluctuations and it provides a continuous power flow. Batteries are the most economical and commonly used energy storage devices in medium power. For the controlled power flow between batteries and rest of the system a bidirectional converter is used.

In a conventional two-stage bidirectional converter, power is processing in both stages with a high-frequency switching. In a two stage bidirectional converter it has a dc-dc converter for the conversion of the battery voltage to dc link voltage and a dc-ac converter for the dc link voltage to grid voltage. Hence in two stage converters two controllers are required for each stage. Thus the overall efficiency decreases because it is the product of efficiency at each stage. Also the circuit has high switching and conduction losses, due to gate drive circuits. Thus conventional two-stage bidirectional converters are not cost effective and it has very complex circuit and thus it is less efficient [4].

In the single-stage bidirectional converter, there is only a single power-conversion stage with a single high frequency switching for the dc-ac power conversion, resulting in higher efficiency, and cost effective than conventional two-stage converters. Thus, single-stage bidirectional power converters have enhanced system reliability, improved system efficiency, and a less complex circuit than a two-stage bidirectional converter [1].

This paper presents a modified non isolated single stage power converter with the same control algorithm. The isolated dc-dc converter is replaced with a non-isolated topology. By avoiding the high frequency transformer in the dc-dc converter the high frequency switching can be avoided which means the control circuit is less complicated and the overall efficiency and gain of the circuit is improved. The feed forward control system provides seamless mode transition in charging and discharging modes. Thus size and weight can be reduced. From the above, it can be inferred that this topology can be developed in a cost effective manner.

\section{PROPOSED SYSTEM}

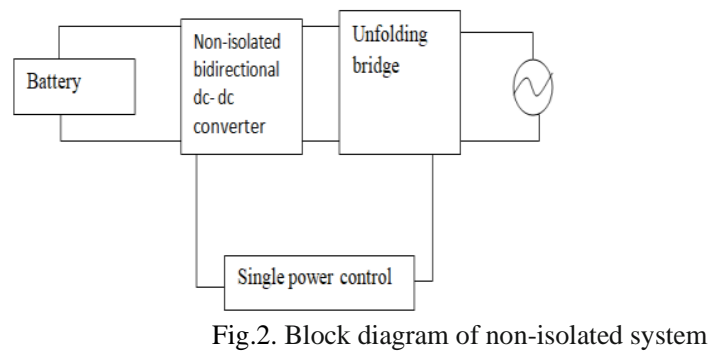

The block diagram consists of battery source, non isolated dcdc converter, and an inverter, both are using single power control. The input de voltage is given to the bidirectional converter by using a battery, where the voltage is stepped up or down to the required voltage level. From the converter circuit, voltage is given to the full bridge inverter. Output ac voltage from the inverter is connected to grid via a filter circuit. A transformer less bidirectional Single-stage dc-ac converter is introduced. The proposed inverter has seven switches and is capable of working in both buck and boost modes of operation.

\section{OPERATION OF THE PROPOSED SYSTEM}

Fig.3. below represents the proposed system. Here $\mathrm{C}_{3}$ is the capacitor which links the dc circuit. At the input voltage is provided by battery which is connected to non-isolated dc-dc converter, switch $\mathrm{s}_{1}$ to $\mathrm{s}_{4}$ constitutes the unfolding bridge. In the proposed system a transformer-less topology is used .The coupled inductor is used which has the primary inductance $L_{P}$ and secondary inductance $L_{s}$ is tightly coupled on the 
same ferrite core, which increases the voltage diversity on both buck and boost modes. $\mathrm{D}_{1}$ corresponds the duty ratio of $\mathrm{S}_{11}$ and $\mathrm{S}_{12}$, where D3 represents the duty ratio of switch $\mathrm{S}_{13}$.

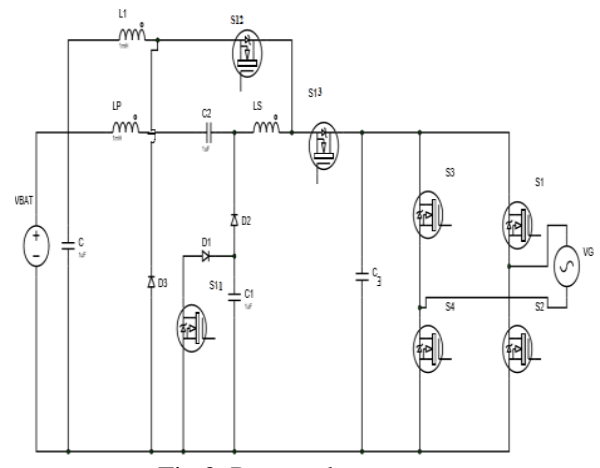

Fig.3. Proposed converter

Both D1 and D3 are related to each other by D1(=1-D3). The coupled inductor can be assigned as an ideal transformer with the magnetizing inductor $\mathrm{Lm}$ and turns ratio $\mathrm{N}(=\mathrm{N} 2 / \mathrm{N} 1)$, where $\mathrm{N} 1$ is the primary number of turns and $\mathrm{N} 2$ is the secondary number of turns of the coupled inductor.

Here input dc voltage is given to the boost circuit where it is stepped up to a required voltage level. From the boost circuit the stepped up dc voltage is given to the full bridge inverter and dc to ac conversion take place. This ac voltage is given to the load via the filter. In boost mode, the non isolated converter boosts up the low input voltage to high dc-link voltage and the switch S2 remains OFF during this mode. The proposed system has four modes of operation. The four operating modes are:

A. MODE 1: During mode1, switch $\mathrm{S}_{11 \text { was }} \mathrm{ON}$, whereas switch $\mathrm{S}_{13}$ was OFF. Low-battery bank voltage is applied to the circuit. Capacitor $\mathrm{C}_{2}$ remains charged before mode1 and $\mathrm{i}_{\mathrm{LM}}$ increases linearly.

B. MODE 2: Switch $S_{11}$ turns OFF in mode 2. The capacitance across switch $S_{11}$ is charged by primary current $i_{L P}$, capacitance across switch $\mathrm{S}_{13}$ and is discharged by the secondary current $i_{\text {LS }}$. This mode completes when the voltage across switch $S_{11}$ is equal to the capacitor voltage $\mathrm{V}_{\mathrm{C} 1}$,

C. MODE 3:. Since switch $S_{11}$ is OFF, due to leakage inductance the primary current $i_{\mathrm{LP}}$ start decreasing while the secondary current $i_{L S}$ goes down. Hence, the body diode of switch $\mathrm{S}_{13}$ turns ON. Through diode D1 Capacitor $\mathrm{C}_{1}$ starts charging because the voltage across capacitor $\mathrm{C}_{1}$ is get lower than the voltage across switch S1. Hence the voltage stress across switch $S_{1}$ is decreased

D. MODE 4: During the ZVS Switch $S_{13}$ turns ON. For the transfer of energy to the inverter side of the circuit the two windings of the coupled inductor and $\mathrm{C}_{2}$ capacitor are all now connected in series. $i_{L S}$ goes up until it reaches $i_{L P}$, then it follows $i_{L P}$ until the end of mode 4 . Thus, the energy stored in both windings are dissipates across the inverter side of the circuit. In this mode D1 and D2 are in off condition.

E. MODE 5: In this mode, switch $S_{13}$ turns OFF. The parasitic capacitance of switch $\mathrm{S}_{13}$ is charged by the current $\mathrm{i}_{\mathrm{LS}}$ Capacitor $\mathrm{C}_{1}$ starts discharging across capacitor $\mathrm{C}_{2}$, through diode $\mathrm{D}_{2}$

Gboost $=\mathrm{VH} / \mathrm{VL}$

\begin{tabular}{|c|r|r|r|}
\hline Switch & \multicolumn{1}{|c|}{$\mathrm{S}_{11}$} & \multicolumn{1}{|c|}{$\mathrm{S}_{12}$} & \multicolumn{1}{|c|}{$\mathrm{S}_{13}$} \\
\hline MODE1 & 1 & 0 & 0 \\
\hline MODE2 & 0 & 0 & 0 \\
\hline MODE3 & 0 & 0 & 0 \\
\hline MODE4 & 0 & 0 & 1 \\
\hline MODE5 & 0 & 0 & 0 \\
\hline MODE6 & 1 & 0 & 0 \\
\hline
\end{tabular}

Table.1. Switching states of the proposed system in boost mode

F MODE 6: During Mode6, switch $S_{11}$ is turns $O N$ due to the ZVS. Hence $S_{11}$ is not accepting any current from the clamped circuit, the switching losses becomes decrease due to ZVC, and gets an improved efficiency. The next switching cycle starts when $\mathrm{V}_{\mathrm{C} 1}=\mathrm{V}_{\mathrm{C} 2}$, and repeats the cycle.

\section{CONTROL SECTION}

In this converter the grid current io is controlled in the power processing stage. The primary switch duty $\mathrm{D}$ can be reexpressed as the sum of two duty terms as follows: $\mathrm{D}=(\mathrm{Dp}$ $+\Delta \mathrm{D})$. $\mathrm{Dp}$ is the steady-state duty and $\Delta \mathrm{D}$ is the control duty. The sign of the reference current Ig determines the direction of the power flow for the selected mode. The control block diagram of the proposed transformerless bidirectional converter is shown in Fig. 4. Dp is shared in both charge and discharge modes by using a fed forward voltage compensator so that an easy control environment is obtained by presetting an operating point. Seamless mode transition can be obtained due to these features. The power flow direction and power value are calculated only by the reference grid current Ig. In a steadystate condition $\Delta \mathrm{D}$ is not sufficient to achieve precise tracking because it results in periodic errors.

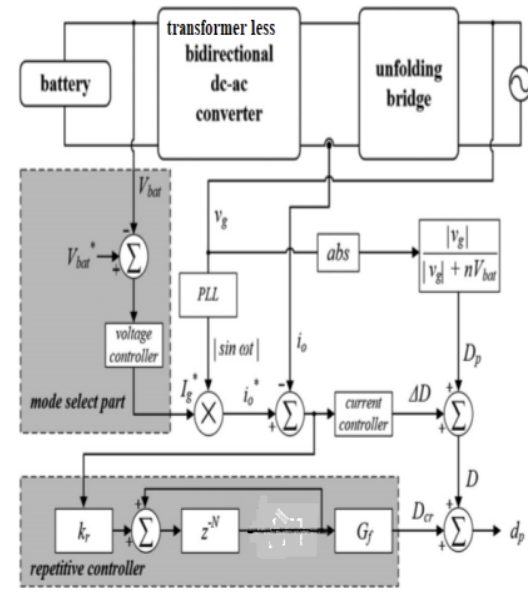

Fig.4. Control system block diagram 
So that, a repetitive control duty $\Delta$ Drc should provide better control input responses for the grid current and the zero steady state error tracking. Therefore the control system is a developed one and is very suitable for reference current tracking and seamless mode transition.

\section{SIMULATION RESULTS}

The proposed system is simulated in MATLAB/SIMULINK. The simulation model is shown in Fig.5.a and 5.b.Figure 5a shows the simulink model view from battery side and 5.b shows the simulink model view from grid side.

Table 2 .proposed system parameters

\begin{tabular}{|c|c|}
\hline Parameters & Values \\
\hline $\mathrm{C}$ & $10 \mu \mathrm{F}$ \\
\hline $\mathrm{C}_{1}$ & $4.4 \mu \mathrm{F}$ \\
\hline $\mathrm{C}_{2}$ & $4.4 \mathrm{Nf}$ \\
\hline $\mathrm{L}_{1}$ & $80 \mu \mathrm{H}$ \\
\hline $\mathrm{L}_{\mathrm{m}}$ & $24 \mu \mathrm{H}$ \\
\hline $\mathrm{N}$ & 2.5 \\
\hline $\mathrm{C}_{\mathrm{F}}$ & $800 \mathrm{nF}$ \\
\hline $\mathrm{L}_{\mathrm{F}}$ & $400 \mu \mathrm{H}$ \\
\hline
\end{tabular}

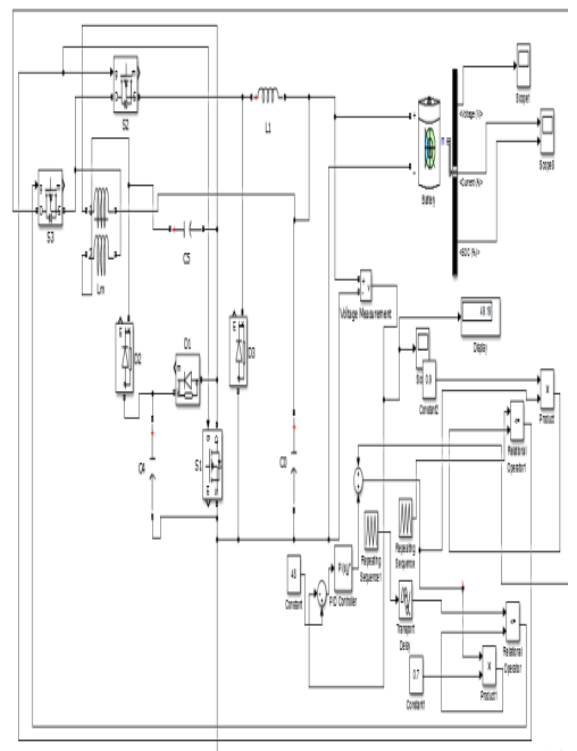

Fig5.a, Simulink model of the proposed system at battery side

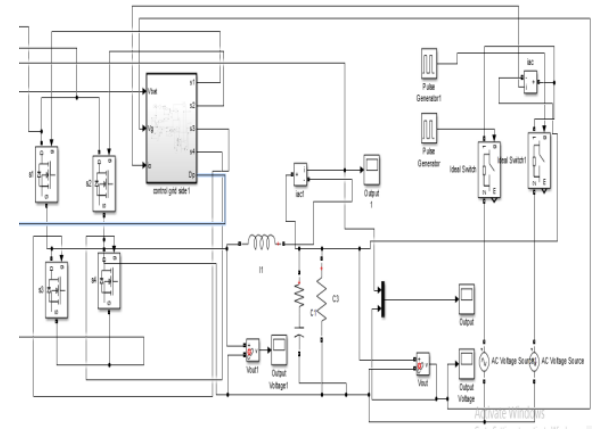

Fig.5.b. Simulink model of the proposed system at grid side

Here $48 \mathrm{~V}$ dc is provided at the input side. This dc voltage is then given to the boost circuit. From the boost circuit stepped up voltage is given to the full bridge inverter. When simulated output ac voltage from the full bridge inverter is $230 \mathrm{~V}_{\mathrm{rms}}$ is obtained. Fig.8.and Fig.9 shows the input and output waveform of the proposed system.

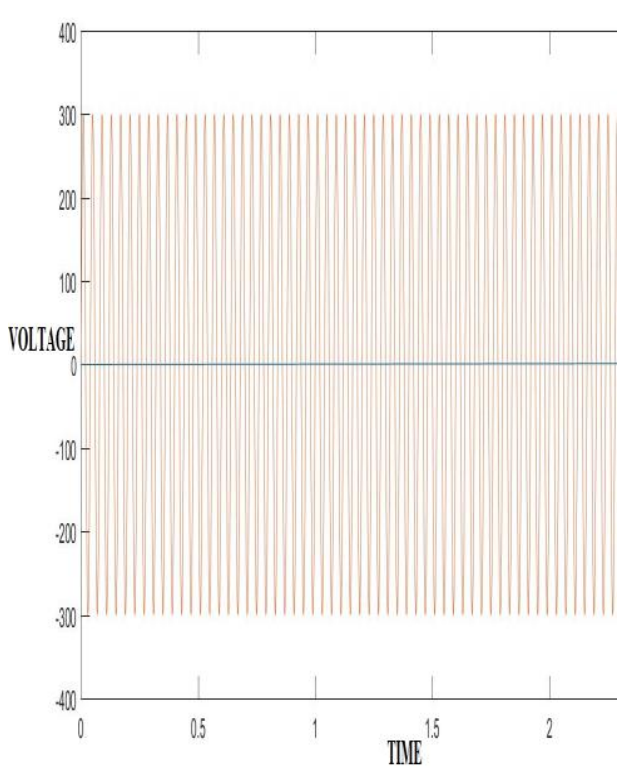

Fig.9. Output ac voltage

There is a voltage perturbation is applied on the grid at $1 \mathrm{sec}$ ond and the perturbation is lasts for 1 second. After $1 \mathrm{~s}$ the system regains its original state.

Another advantage of proposed system is improved gain. On calculating the gain the existing system has voltage gain 10 and the proposed system has an improved voltage gain which is equal to 12 . 


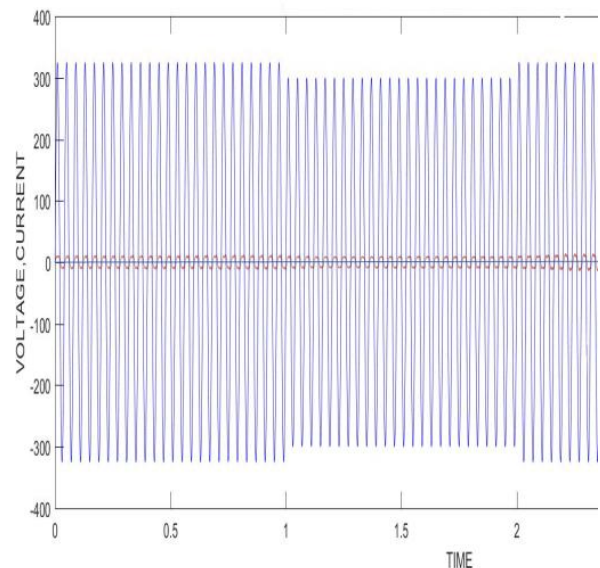

Fig.8. Output ac voltage and current waveform of the proposed system with grid voltage perturbation

Table; 3 comparison of existing and proposed system

\begin{tabular}{|c|c|c|}
\hline $\begin{array}{c}\text { Param- } \\
\text { eters }\end{array}$ & $\begin{array}{c}\text { Existing } \\
\text { system }\end{array}$ & $\begin{array}{c}\text { Proposed } \\
\text { System }\end{array}$ \\
\hline $\begin{array}{c}\text { Input } \\
\text { voltage }\end{array}$ & $48 \mathrm{~V}$ & $24 \mathrm{~V}$ \\
\hline $\begin{array}{c}\text { Output } \\
\text { voltage }\end{array}$ & $230 \mathrm{~V}_{\text {rms }}$ & $230 \mathrm{~V}_{\text {rms }}$ \\
\hline $\begin{array}{c}\text { Voltage } \\
\text { gain }\end{array}$ & 8 & 10 \\
\hline $\begin{array}{c}\text { Size and } \\
\text { weight }\end{array}$ & Bulky & Small \\
\hline
\end{tabular}

\section{CONCLUSION}

A single stage transformerless dc-ac converter is proposed. It can be used for photo voltaic grid connected systems and low input battery voltage applications. In the existing system, transformer used for isolation purpose increases core losses in the system. It also makes the system bulkier and costlier. Increase in core losses reduces efficiency of the system. To overcome this problem transformer less topology is adopted. This configuration has higher efficiency. Since transformer is avoided it reduces the size and weight of the system, making the system efficient and cost effective. Large voltage diversity is obtained in all modes of operation due to the ZVS operation. This helps the circuit to boost up the low-input voltage to high dc-link voltage, and vice versa. The control algorithm consists of a feed-forward nominal voltage compensator and a repetitive control scheme. The feed-forward nominal voltage compensator provides an easier current control.

\section{REFERENCES}

[1] Owon Kwon , Jun-Seok Kim, Jung-Min Kwon, Member, IEEE, "Bidirectional Grid-Connected Single-Power-Conversion Converter With Low-Input Battery Voltage", IEEE Transactions on industrial electronics, vol. 65, no. 4, April 2018

[2] Muhammad Aamir, Saad Mekhilef, Member, IEEE "High-Gain Zero-Voltage Switching Bidirectional Converter With a Reduced Number of Switches,", IEEE transactions on circuits and systems-ii, express briefs, vol. 62, no. 8, August 2015

[3] A. K han, H. Cha, F. Ahmed, J. Kim, and J. Cho, "A highly reliable and high efficiency quasi single-stage buck-boost inverter," IEEET rans Power Electron vol. 32, no. 6, pp. 4185-4198, , , Jun. 2017

[4] W.Chen, R. Zane, and L. Corradini "Isolated bidirectional grid tied three-phase AC-DC power conversion using series resonant converter modules and a three-phase unfolder" ,IEEE Trans.PowerElectron. vol. 32, no. 12, pp. 9001-9012 Dec. 2017

[5] Y.-W. Cho, W.-J. Cha, J.-M. Kwon, and B.-H. Kwon "Highefficiency bidirectional DAB inverter using a novel hybrid modulation for standalone power generating system with low input voltage", , IEEE Trans. Power Electron., vol. 31, no. 6, pp. 4138-4147, Jun. 2016

[6] M. Kwon, S. Oh, and S. Choi, "High gain soft-switching bidirectional DC-DC converter for eco-friendly vehicles," IEEE Trans. Power Electron., vol. 29, no. 4, pp. 1659-1666, Apr. 2014.

[7] B. J. Vermulst, J. L. Duarte, C. G. Wijnands, and E. A. Lomonova, "Quad active-bridge single-stage bidirectional three-phase AC-DC converter with isolation: Introduction and optimized modulation," IEEE Trans. Power Electron., vol. 32, no. 4, pp. 2546-2557, Apr. 2017.

[8] Y.-P. Hsieh, J.-F. Chen, L.-S. Yang, C.-Y. Wu, and W.-S. Liu, "High conversion-ratio bidirectional DC-DC converter with coupled inductor," IEEE Trans. Ind. Electron., vol. 61, no. 1, pp. 210-222, Jan 2014.

[9] H. Wu, K. Sun, L. Chen, L. Zhu, and Y. Xing, "High step-up/stepdown soft-switching bidirectional DC-DC converter with coupledinductor and voltage matching control for energy storage systems," IEEE Trans. Ind. Electron., vol. 63, no. 5, pp. 2892-2903, May 2016.

[10] N. M. L. Tan, T. Abe, and H. Akagi, "Design and performance of a bidirectional isolated DC-DC converter for a battery energy storage system," IEEE Trans. Power Electron., vol. 27, no. 3, pp. 1237-1248 Mar. 2012 